Jurnal Pengurusan 61(2021) $109-120$

https://doi.org/10.17576/pengurusan-2021-61-09

\title{
Keupayaan Pelaksanaan Inovasi Produk dalam Program Homestay di Semenanjung Malaysia
}

\author{
(The Capability of Product Innovation Implementation in Homestay Program at Peninsular Malaysia)
}

\author{
Suhaida Herni Suffarruddin \\ Mastura Jaafar \\ Suraiyati Rahman \\ (Pusat Pengajian Perumahan, Bangunan dan Perancangan, Universiti Sains Malaysia)
}

\begin{abstract}
ABSTRAK
Inovasi merupakan aspek yang penting dalam sektor pelancongan. Persekitaran luaran yang semakin mencabar mendorong sesebuah perniagaan untuk berinovasi supaya dapat terus berdaya saing. Program homestay merupakan satu bentuk aktiviti pelancongan luar bandar yang mempunyai keunikan tersendiri dan berpotensi menyumbang kepada pembangunan sosio-ekonomi masyarakat setempat. Namun, limitasi kesedaran pengusaha program homestay terhadap kepentingan pelaksanaan inovasi boleh menyebabkan sebilangan program homestay tidak berdaya saing. Kajian ini bertujuan untuk menkaji keupayaan pelaksanaan inovasi produk dan mengenal pasti faktor penentu yang mempengaruhi inovasi tersebut dalam program homestay. Lapan buah program homestay di Semenanjung Malaysia telah dipilih berdasarkan kepada beberapa kriteria yang telah ditetapkan. Temu bual bersemuka telah dijalankan bersama penyelaras program homestay yang terlibat dan teknik analisis kandungan digunakan dalam analisis data. Dapatan kajian menunjukkan inovasi produk yang paling ketara dilaksanakan ialah peningkatan kualiti penginapan, keunikan pakej aktiviti desa dan perkembangan perusahaan industri kecil dan sederhana. Manakala empat faktor penentu inovasi yang ditemui adalah orientasi pasaran, semangat keusahawanan, sokongan kerajaan dan pengetahuan. Implikasi praktikal kajian ini adalah sumbangan data empirikal yang dapat digunakan oleh pihak industri sebagai panduan untuk menaik taraf program homestay di Malaysia supaya lebih berdaya maju.
\end{abstract}

Kata kunci: Inovasi produk; faktor penentu inovasi; program homestay; pelancongan luar bandar; Semenanjung Malaysia.

\section{ABSTRACT}

Innovation is an essential aspect of the tourism sector. The increasingly challenging external environment is forcing businesses to innovate for continuously competitive. A homestay program is a form of rural tourism activity that has its uniqueness and potential to contribute to the socio-economic development of the local community. However, a lack of awareness among homestay operators of the importance of innovation implementation leads to some homestay programs' incompetence. This study aims to explore the capability of product innovation implementation; and had identified determinant factors that influence innovation implementation in the homestay program. In total, eight homestay programs at Peninsular Malaysia were selected based on several criteria. Face-to-face interviews were conducted with the homestays' coordinators, and the collected data were analysed using the content analysis technique. Results have shown that the most significant product innovation in the homestay programme in the case study area is improving accommodation quality, uniqueness of rural activity packages, and enhancement of small-medium enterprise business. In addition, four determinant factors were found, including market orientation, entrepreneurial spirit, government support, and knowledge. The practical implication is that industry players can utilise the empirical data as a benchmark to upgrade the other program homestay in Malaysia to be more competitive.

Keywords: Product innovation; determinant factor; homestay program; rural tourism; Peninsular Malaysia.

\section{PENGENALAN}

Inovasi semakin diberi perhatian dalam dunia perniagaan masa kini melalui penerokaan peluang baharu dengan melaksanakan pembaharuan dan penambahbaikan (Hjalager 2010) untuk meningkatkan kebolehpasaran produk (Gunday et al. 2011). Pengetahuan dan keupayaan untuk berinovasi amat penting bagi penawaran produk yang bernilai kepada pelanggan (Crumpton 2012).
Keperluan berinovatif merupakan satu anjakan bagi sesebuah perniagaan untuk terus berdaya maju dalam pasaran global yang sangat kompetitif (Divisekera \& Nguyen 2018). Begitu juga sektor pelancongan yang telah menunjukkan perkembangan yang amat memberangsangkan dan turut menjadi sektor ekonomi yang paling berdaya saing (Backman Klaesson \& Öner 2017). Ini termasuklah pelancongan luar bandar yang dilihat amat berpotensi untuk menyediakan destinasi 
yang mempunyai keunikan dan keaslian produk tersendiri meliputi keindahan alam semula jadi, kepelbagaian adat resam dan budaya tempatan (Mapjabil \& Ismail 2015).

Program homestay merupakan salah satu pelancongan luar bandar yang begitu popular di Malaysia. Ianya telah diwujudkan sejak tahun 1995 bertujuan untuk menawarkan pengalaman menarik kepada pelancong (Ramele \& Yamazaki 2020) merangkumi penginapan, penyediaan makanan dan minuman, pakej aktiviti dan perusahaan produk komuniti (Suffarruddin et al. 2017). Perkembangan yang begitu pantas terutamanya dalam bidang teknologi telah membuka peluang kepada pengusaha Program Homestay untuk meluaskan perniagaan mereka (Osman \& Zakaria 2020). Tambahan lagi, setiap program homestay mempunyai keunikan produk tersendiri dan mereka digalakkan untuk melaksanakan inovasi bagi memenuhi permintaan dan kepuasan pelancong (Hussin \& Kunjuraman 2014). Rancangan Malaysia ke-9 telah menekankan kelebihan ini sebagai satu peluang untuk komuniti luar bandar meningkatkan tahap pendapatan dan mengurangkan jurang kemiskinan (EPU 2015). Selaras dengan itu, pelbagai aktiviti penjanaan ekonomi baharu telah disuntik dalam program homestay (Kasim et al. 2016) bagi mencapai hasrat ini sekaligus membangunkan sosioekonomi komuniti terlibat.

Walaupun begitu, terdapat sebilangan program homestay yang masih menawarkan perkhidmatan yang sama sehingga menjejaskan minat pelancong (Hussin \& Kunjuraman 2014). Ini kerana terdapat beberapa pengusaha yang kurang berpengalaman dan berpengetahuan dalam menguruskan perniagaan serta kurang mendapat pendedahan tentang inovasi pelancongan (Sakdiyakorn \& Sivarak 2016). Keadaan ini telah menjejaskan bilangan kedatangan pelancong sehingga mengurangkan jumlah pendapatan pengusaha dan seterusnya menyebabkan mereka tidak mampu untuk bertahan lagi (Kasim et al. 2016). Data daripada MOTAC (2020) juga menunjukkan hampir 60 peratus program homestay mengalami kadar penurunan yang kerap bagi jumlah kedatangan pelancong sepanjang tahun 2011 hingga 2019.

Berdasarkan kepada kajian terdahulu, tumpuan terhadap inovasi produk dalam industri pelancongan adalah terhad (Alsos et al. 2014; Martinez-Roman et al. 2015; Sakdiyakorn \& Sivarak 2016) kerana pengkaji lebih memfokuskan kepada inovasi dalam sektor pembuatan (Al-Ansari et al. 2013; Boachie-Mensah \& Acquah 2015; Kafetzopoulos \& Psomas 2015; Rosli \& Sidek 2013). Tambahan lagi, kebanyakan kajian berkaitan inovasi dalam pelancongan hanya fokus secara konsep melibatkan keperluan dan halangan kepada inovasi (Birgit et al. 2018; Najda-Janoszka \& Kopera 2014). Begitu juga dengan kajian inovasi produk dalam program homestay yang sukar ditemui berbanding kajian dalam industri perhotelan (Nicolau \& Santa-María 2013; Nieves et al. 2014), perkhidmatan penginapan dan makanan (Martinez-Roman et al. 2015), pelancongan budaya warisan (Sakdiyakorn \& Sivarak 2016) dan pelbagai perusahaan pelancongan lain (Aldebert et al. 2011). Di Malaysia pula, penyelidikan tentang inovasi produk dalam program homestay hanya melibatkan beberapa kawasan tertentu sahaja seperti penyelidikan di Negeri Sarawak (Keling \& Entebang 2017) dan Negeri Kedah (Suffarruddin et al. 2017; Hashim et al. 2015).

Pendedahan terhadap faktor penentu yang mempengaruhi inovasi dalam sektor pelancongan juga kurang ditemui dalam kajian terdahulu, sedangkan ianya amat penting untuk mengenal pasti dorongan utama berlakunya inovasi (Martinez-Roman et al. 2015; Raffai 2013; Sakdiyakorn \& Sivarak 2016). Sejajar dengan itu, kajian ini bertujuan untuk (1) menerokai keupayaan pelaksanaan inovasi produk, dan seterusnya (2) mengenal pasti faktor penentu yang mempengaruhi berlakunya inovasi tersebut. Kajian ini juga diharapkan dapat menyumbang kepada memperkayakan ilmu pengetahuan berkaitan keupayaan untuk melaksanakan inovasi dalam program homestay.

\section{SOROTAN LITERATUR}

Konsep inovasi telah diperkenalkan oleh Schumpeter (1934) yang memfokuskan kepada pembangunan ekonomi dan keusahawanan. Beliau mentakrifkan inovasi sebagai penciptaan produk baharu atau penambahbaikan terhadap produk sedia ada dengan menggunakan kaedah baharu untuk mewujudkan pasaran baharu dan membangunkan perniagaan. Definisi ini turut dipersetujui oleh beberapa sarjana dengan merujuk inovasi sebagai penghasilan sesuatu yang baharu untuk meningkatkan keupayaan produk (Kuratko \& Hodgetts 2004; Tidd et al. 2005) agar dapat menerokai peluang baharu dan lebih berdaya saing. Konsep ini dilihat boleh disesuaikan dengan industri perkhidmatan termasuklah sektor pelancongan (OECD 2005) yang turut menawarkan produk dan pakej pelancongan yang lebih kreatif untuk menarik kedatangan pelancong (Keling \& Entebang 2017).

Inovasi produk pula merujuk kepada percambahan idea-idea baharu dengan melakukan pembaharuan dan penambahbaikan terhadap spesifikasi tertentu (OECD 2005) untuk memenuhi kepuasan pelanggan (Chang, Linton \& Chen 2012). Tambahan lagi, produk yang dihasilkan mestilah mempunyai keaslian serta keunikan tersendiri untuk dikormesialkan (Hjalager et al. 2018). Penciptaan produk yang menarik perhatian pengguna merupakan inovasi yang berupaya menyumbang kepada pertumbuhan pasaran (Boachie-Mensah \& Acquah 2015). Sejajar dengan konteks ini, inovasi produk menjadi salah satu usaha yang perlu dilakukan secara berterusan agar tahap kecekapan organisasi dapat dipertingkatkan (Abdul Aziz et al. 2014; Kafetzopoulos \& Psomas 2015).

Inovasi produk juga penting bagi sektor pelancongan kerana ianya dapat menonjolkan kelainan sesuatu produk dan berupaya mewujudkan pasaran baharu sekaligus meningkatkan jualan sektor tersebut (Divisekera \& Nguyen 2018). Inovasi yang dilaksanakan oleh pemain 
industri adalah melibatkan penghasilan barangan atau aktiviti baharu yang boleh ditawarkan kepada pelancong (Aldebert et al. 2011). Kajian Sakdiyakorn dan Sivarak (2016) terhadap pelancongan warisan budaya membuktikan bahawa inovasi produk penting untuk mencapai matlamat dan menyokong pembangunan pelancongan komuniti. Ini dibuktikan melalui inovasi yang dilakukan iaitu dengan membuat transformasi terhadap rumah di sepanjang terusan dan dijadikan homestay. Selain itu, kajian Keling dan Entebang (2017) mendapati pelbagai aktiviti baharu telah diperkenalkan dalam program homestay di Sarawak yang bertujuan untuk menarik minat pelancong di samping memaparkan gaya hidup dan budaya masyarakat setempat.

Pelaksanaan inovasi produk juga dipercayai adalah dipengaruhi oleh beberapa faktor penentu (Hjalager 2010). Ini berdasarkan kepada kajian terdahulu yang membuktikan bahawa sesebuah perniagaan akan melakukan inovasi terhadap produk yang ditawarkan disebabkan oleh beberapa faktor penentu (MartinezRoman et al. 2015; Mei, Arcodia \& Ruhanen 2011; Nieves et al. 2014; Raffai 2013; Ronningen 2010; Sakdiyakorn \& Sivarak 2016). Antara faktor penentu yang ditemui oleh penyelidik ialah (1) pengetahuan, (2) semangat keusahawanan, (3) orientasi pasaran, dan (4) sokongan kerajaan. Sejajar dengan itu, penerokaan yang lebih mendalam perlu dilakukan bagi mengenal pasti faktor penentu yang mendorong berlakunya inovasi produk dalam program homestay. Perbincangan berikutnya adalah berkaitan beberapa faktor penentu yang telah dibincangkan dalam kajian terdahulu.

Pengetahuan Pengetahuan merupakan cabang ilmu dan kemahiran yang dimiliki secara individu atau berkumpulan (Ronningen 2010) untuk meningkatkan kebolehan dalam kalangan pekerja (Hjalager 2010) dan dikenal pasti menjadi teras kepada proses menjana inovasi (Martinez-Roman et al. 2015). Pengetahuan boleh dikategorikan sebagai pengetahuan asas dan teknologi yang berperanan meningkatkan pengeluaran produk dalam pelbagai sektor (Aldebert et al. 2011). Dalam industri pelancongan, pengetahuan yang diperolehi daripada dalam dan luar organisasi (Camisón \& Monfort-Mir 2012) berupaya untuk menghasilkan nilai tambah dan meningkatkan hasil sesebuah perniagaan (Tajeddini, Martin \& Altinay 2020). Ini dibuktikan dalam kajian Martinez-Roman et al. (2015) yang mendapati bahawa pengetahuan dalam kalangan pekerja telah membantu usaha untuk mendapatkan idea baharu. Seiring dengan kajian Nieves et al. (2014) terhadap pelancongan perhotelan yang mengakui bahawa penguasaan ilmu berkaitan persekitaran perniagaan telah berupaya mendorong peningkatan aktiviti inovasi.

Semangat Keusahawanan Faktor ini adalah berdasarkan kepada inisiatif individu dalam melakukan pembaharuan untuk terus berdaya maju (Hjalager 2010). Semangat keusahawanan boleh ditemui dalam diri individu yang mempunyai kualiti dan keupayaan sebagai penggerak
(Sakdiyakorn \& Sivarak 2016) untuk berjuang, berani mengambil risiko dan mampu mencipta sesuatu yang baharu (Croitoru 2012). Sakdiyakorn dan Sivarak (2016) membuktikan semangat keusahawanan yang dimiliki oleh pengusaha dan komuniti setempat telah menjana pelbagai idea melalui minda yang kreatif dan kesediaan menerokai peluang yang lebih baik. Tambahan lagi, semangat untuk meningkatkan pasaran dan pendapatan juga mendorong usahawan menjadi lebih berinovasi (Galindo \& Méndez-Picazo 2013).

Orientasi Pasaran Faktor ini merupakan usaha bagi memenuhi keperluan pelanggan dan sekaligus mempengaruhi aktiviti inovasi. Orientasi pasaran dilihat sebagai pengaruh kepada peningkatan prestasi yang lebih positif dalam pelbagai sektor perniagaan (Chang et al. 2014). Sektor pelancongan juga mendapati bahawa kesedaran terhadap permintaan dan kehendak pelancong adalah penting (Raffai 2013) sebagai dorongan kepada penerokaan peluang baharu dan peningkatan daya saing (Sakdiyakorn \& Sivarak 2016). Menurut Bodlaj, Coenders dan Zabkar (2012), kejayaan dalam pasaran perniagaan adalah berdasarkan kepada tindakan proaktif yang dilakukan terhadap orientasi pasaran. Kajian terdahulu juga membuktikan orientasi pasaran mempunyai pengaruh yang kuat terhadap pelaksanaan inovasi produk dengan meningkatkan pengeluaran produk baharu dan seterusnya berjaya bersaing dengan pasaran sedia ada (Chang et al. 2014; Martinez, Serna \& Guzman 2018).

Sokongan Kerajaan Sokongan kerajaan adalah salah satu faktor penentu yang penting untuk menggalakkan inovasi terutamanya bagi Industri Kecil dan Sederhana (IKS) (Mei et al. 2011). Penglibatan pelbagai pihak berkepentingan amat diperlukan dalam merancang dan melaksanakan pelbagai usaha (Alberti \& Giusti 2012). Dalam industri pelancongan yang memberi penekanan terhadap hubungan baik yang diwujudkan (Hjalager 2010; Ronningen 2010), pemberian intensif dan kemudahan saluran kewangan dilihat mampu mendorong sesebuah perniagaan menjalankan inovasi yang lebih baik (Martinez-Roman et al. 2015). Kajian terdahulu juga membuktikan jalinan kerjasama ini telah membantu dalam perkembangan idea baharu yang dapat menyumbang kepada pencapaian inovasi (Nieves et al. 2014; Sakdiyakorn \& Sivarak 2016). Sementara itu, di peringkat komuniti pula, kerjasama sebegini merupakan kunci kepada kestabilan pembangunan dan keupayaan menuju ke arah pencapaian matlamat yang lebih besar (Kalyani 2011).

\section{PROGRAM HOMESTAY DI MALAYSIA}

Di Malaysia, program homestay juga dikenali sebagai inap desa (Hussin \& Kunjuraman 2014; Ahmad et al. 2010) dan merupakan salah satu produk pelancongan yang telah diperkenalkan oleh Kementerian Pelancongan, Seni dan Budaya Malaysia (MOTAC) bagi membolehkan 
pelancong merasai pengalaman kehidupan dan budaya yang berbeza (Ahmad et al. 2014). Program homestay merujuk kepada pengalaman pelancong tinggal bersama keluarga angkat, berinteraksi, menimba pengalaman kehidupan seharian dan mempelajari budaya komuniti luar bandar (MOTAC 2020). Pengalaman yang disediakan adalah berbeza mengikut lokasi dan kepelbagaian etnik kehidupan (Bhuiyan et al. 2012) yang meliputi aktiviti budaya dan ekonomi setempat (Keling \& Entebang 2017). Setiap program homestay diketuai oleh seorang individu yang dikenali sebagai penyelaras dan dikendalikan oleh peserta yang terlibat. Penyelaras bertanggungjawab untuk memimpin dan memantau operasi bagi memastikan kejayaan program homestay masing-masing (Mapjabil et al. 2017; Razzaq et al. 2011). Manakala peserta adalah terdiri daripada pengusaha homestay, usahawan desa dan komuniti yang sentiasa memberi sokongan serta komitmen yang sewajarnya (Ibrahim \& Razzaq 2010; Keling \& Entebang 2017).

Secara umumnya, produk yang disediakan adalah merangkumi penginapan, pengalaman melalui pakej aktiviti desa, dan perusahaan IKS (Suffarruddin et al. 2017; Aziz \& Othman 2015). Penginapan adalah merujuk kepada tempat tinggal yang disediakan oleh pengusaha dengan memberi peluang kepada pelancong tinggal bersama tuan rumah dan mempelajari cara hidup keluarga tersebut (Hussin \& Kunjuraman 2014). Pengalaman pakej aktiviti desa pula meliputi budaya, gaya hidup, aktiviti ekonomi, rekreasi dan pemuliharaan alam sekitar (MOTAC 2020). Ini termasuk daya tarikan sedia ada seperti makanan tradisional, keunikan budaya komuniti, kesenian dan kebudayaan, seni bina rumah dan persekitaran semula jadi kampung (Mapjabil \& Ismail 2015). Tambahan lagi, program homestay sememangnya mempunyai daya tarikan tersendiri seperti alam semula jadi, sejarah, seni dan kraftangan, aktiviti budaya, makanan tradisional, dan aktiviti pertanian (Razzaq et al. 2011). Perusahaan IKS merujuk kepada produk yang diusahakan oleh komuniti untuk dipasarkan kepada pelancong dan dijadikan sebagai cenderahati (Ahmad et al. 2011; Ismail 2015).

Pada awal pengenalan program ini, penyertaan adalah melibatkan beberapa buah kampung yang terpilih dan dilaksanakan secara kecil-kecilan sahaja. Namun kini, program homestay dilihat semakin berkembang dengan penglibatan komuniti yang semakin bertambah. Data yang diperolehi daripada MOTAC (2020) menunjukkan bilangan program homestay yang berdaftar pada tahun 2019 telah meningkat kepada 222 kluster berbanding tahun 2011 yang hanya mempunyai 150 kluster sahaja. Ini membuktikan telah berlakunya pertambahan terhadap bilangan penyertaan komuniti dalam program homestay. Selain itu, statistik kedatangan pelancong juga membuktikan berlakunya peningkatan sebanyak 115 peratus pada tahun 2019 berbanding tahun 2011. Peningkatan ini membuktikan bahawa program homestay telah mendapat tempat sebagai destinasi pelancongan yang digemari oleh pelancong domestik dan antrabangsa.

\section{METODOLOGI}

Pendekatan kualitatif telah digunakan menerusi kaedah temu bual bersemuka separa berstruktur bagi kajian kes yang dipilih untuk mendapatkan maklumat dengan lebih mendalam dan terperinci (Creswell 2014). Penyelidik akan berada dalam situasi responden agar dapat mengetahui keadaan sebenar isu kajian meliputi persekitaran serta bukti yang mencukupi dan dinamakan sebagai kajian kes (Yin 2011). Ini sejajar dengan cadangan penyelidik lepas, bagi menjawab persoalan bagaimana dan mengapa inovasi boleh berlaku (Sakdiyakorn \& Sivarak 2016) terutamanya dalam program homestay (Hashim et al. 2015).

Pemilihan sampel kajian adalah penting untuk memastikan responden dapat memberi data yang paling relevan dan sesuai dengan kajian yang dilakukan (Yin 2011). Kajian ini dimulakan dengan membuat pemilihan sampel berdasarkan rekod kedatangan pelancong yang diperolehi daripada pegawai MOTAC Malaysia di samping memenuhi lima kriteria berikut:

1. Program homestay yang telah ditubuhkan melebihi sepuluh tahun.

2. Program Homestay yang mempunyai sekurangkurangnya 10 pengusaha berdaftar.

3. Program homestay yang masih lagi beroperasi serta aktif menerima kedatangan pelancong sepanjang tahun 2011 hingga 2017.

4. Program homestay mestilah menunjukkan peningkatan peratusan kedatangan pelancong yang positif pada tahun 2017 berbanding tahun 2011.

5. Program homestay yang masih menawarkan pengalaman aktiviti desa.

Proses pengumpulan data dijalankan terhadap lapan buah program homestay yang berdaftar di Semenanjung Malaysia untuk menerokai pelaksanaan inovasi produk dan mengenal pasti faktor penentu inovasi dalam pembangunan program homestay. Dalam kajian ini, penyelaras program homestay dipilih bagi menjawab segala persoalan kerana mereka merupakan individu yang arif mengenai hal ehwal berkaitan pembangunan program homestay masing-masing. Tambahan lagi, ada di antara mereka yang mempunyai pengalaman luas dan pernah menjalankan tanggungjawab bagi meningkatkan ekonomi kampung (Mapjabil et al. 2017). Jadual 1 menunjukkan latar belakang program homestay yang dikaji.

Setiap responden dihubungi terlebih dahulu bagi menjelaskan objektif kajian dan memohon kebenaran untuk melakukan pengumpulan data. Temu bual bersemuka dan lawatan mengambil masa selama tiga hingga empat jam bagi setiap program homestay. Soalan temu bual dirangka secara lebih terbuka untuk 
menggalakkan responden memberikan idea yang tidak terhad. Seterusnya, temu bual yang telah direkod menjalani proses transkripsi dan data tersebut dianalisa menggunakan kaedah analisis kandungan (content analysis). Akhir sekali, data ini dikategorikan secara manual mengikut tema dan sub-tema yang bersesuaian untuk mengenal pasti kewujudan inovasi produk dan faktor penentu inovasi dalam program homestay tersebut.

\section{DAPATAN KAJIAN}

\section{INOVASI PRODUK DALAM PROGRAM HOMESTAY}

Lapan penyelaras yang ditemu bual mengakui telah melakukan inovasi produk terhadap pembangunan program homestay. Inovasi produk yang dilaksanakan terbahagi kepada tiga kategori iaitu (i) peningkatan kualiti penginapan; (ii) keunikan pakej aktiviti desa; dan (iii) perkembangan perusahaan IKS. Ketiga-tiga kategori ini dianalisa berdasarkan kepada dua tahap inovasi iaitu pembaharuan dan penambahbaikan serta dijelaskan mengikut bentuk inovasi yang telah dilaksanakan. Jadual 2 menunjukkan senarai kategori, tahap dan bentuk inovasi tersebut.

Peningkatan Kualiti Penginapan Pembaharuan paling ketara dilaksanakan adalah terhadap kualiti penginapan yang disediakan untuk pelancong dengan memperkenalkan konsep penginapan baharu dikenali sebagai Kampungstay iaitu penginapan secara berasingan dengan tuan rumah. Ini adalah seperti yang dinyatakan oleh responden Homestay C:

"Selepas 5 ke 10 tahun penubuhan, penginapan telah berubah ke arah kampungstay. Kebanyakan pelancong memilih kampungstay iaitu binaan beberapa buah bilik di sebelah rumah homestay".

Penginapan kampungstay turut diperkenalkan oleh pengusaha Homestay A, D, E, F, G dan H. Menurut responden Homestay $\mathrm{F}$, inovasi ini dapat memberi pilihan dan kelainan kepada pelancong dengan menjelaskan:

"Terdapat pelbagai jenis bilik diperbuat daripada kayu dan juga berbentuk kabin. Kita menyediakan bilik standard dan keluarga. Pelancong boleh pilih jenis bilik yang disukai”.

Selain itu, terdapat juga program homestay yang memberi keunikan penginapan yang berbeza kepada pelancong. Sebagai contoh, Homestay D yang telah membina kampungstay berhadapan dengan sawah padi.

Pembaharuan terhadap kualiti penginapan juga adalah dengan pemasangan penyaman udara di dalam bilik sebagaimana dinyatakan oleh responden Homestay A, B, C, D, F, G, dan H. Responden Homestay A menjelaskan:

JADUAL 1. Latar belakang Program Homestay

\begin{tabular}{cccccc}
\hline \multirow{2}{*}{ Responden } & Tahun Beroperasi & Bilangan Pengusaha & \multicolumn{2}{c}{ Bilangan Pelancong } & Peratusan Peningkatan (\%) \\
\cline { 4 - 5 } & & & 2011 & 2017 & \\
\hline Homestay A & 18 tahun & 46 & 7,089 & 10,961 & 54.62 \\
Homestay B & 18 tahun & 20 & 826 & 1,871 & 126.51 \\
Homestay C & 14 tahun & 33 & 2,419 & 7,726 & 219.39 \\
Homestay D & 18 tahun & 20 & 5,533 & 7,668 & 38.59 \\
Homestay E & 18 tahun & 12 & 48,196 & 94,283 & 95.62 \\
Homestay F & 23 tahun & 25 & 1,498 & 9,151 & 510.88 \\
Homestay G & 17 tahun & 19 & 1,168 & 41,375 & $3,442.38$ \\
Homestay H & 13 tahun & 11 & 727 & 3,030 & 316.78 \\
\hline
\end{tabular}

JADUAL 2. Kategori, tahap dan bentuk inovasi, dan Homestay terlibat

\begin{tabular}{llll}
\hline Kategori & Tahap Inovasi & Bentuk Inovasi & Homestay Terlibat \\
\hline $\begin{array}{l}\text { Peningkatan kualiti } \\
\text { penginapan }\end{array}$ & Pembaharuan & Perkenalkan konsep kampungstay & A, C, D, E, F, G dan H \\
& & Pemasangan penyaman udara & A, B, C, D, F, G dan H \\
\multirow{2}{*}{$\begin{array}{l}\text { Keunikan pakej aktiviti } \\
\text { desa }\end{array}$} & Penambahbaikan & Pengubahsuaian bilik air & A, B, C, D, E, F, G dan H \\
& Penambaharuan & Penciptaan aktiviti riadah dan rekreasi & A, B, C, D, E, F dan G \\
\multirow{2}{*}{$\begin{array}{l}\text { Perkembangan perusahaan } \\
\text { IKS }\end{array}$} & Penambahbaikan & Kepelbagaian acara kebudayaan & A, B, C, D, E, F, G dan H \\
& & Penyediaan makanan bervariasi & A, B, D, E dan H \\
\hline
\end{tabular}


"Ramai pengusaha telah memasang penyaman udara dan kebiasaannya bilik ini menjadi pilihan pelancong. Hanya sedikit sahaja bilik yang masih menggunakan kipas".

Ini membuktikan bahawa inovasi ini penting untuk memberi keselesaan kepada pelancong. Walau bagaimanapun, ianya bergantung kepada kemampuan pengusaha yang terlibat.

Selain itu, penambahbaikan turut dilakukan dengan membuat pengubahsuaian terhadap bilik air. Ini diakui oleh responden Homestay D dan E:

"Sebelum ini, bilik air berada di ruangan dapur. Tetapi sekarang, kita telah membina bilik air di dalam setiap bilik bagi memudahkan pelancong menggunakannya pada bila-bila masa dan lebih privasi”. (responden Homestay D).

"Kebanyakan pengusaha telah menukar kepada konsep tandas duduk”. (responden Homestay E).

Inovasi ini turut dilakukan oleh beberapa pengusaha Homestay A, B, C, F, G dan H dan responden mengakui bahawa kebanyakan pelancong cenderung memilih ruang penginapan yang mempunyai bilik air dan tandas duduk, terutamanya pelancong daripada luar negara.

Keunikan Pakej Aktiviti Desa Semua program homestay juga telah melakukan kelainan terhadap pakej aktiviti desa yang ditawarkan. Majoriti penyelaras mengakui telah membuat pembaharuan dengan mencipta aktiviti desa berbentuk rekreasi. Ini dibuktikan oleh responden Homestay B dan C yang menyatakan:

"Homestay ini telah menerokai aktiviti yang berbeza untuk menarik golongan muda dan pelancong antarabangsa iaitu dengan menawarkan aktiviti lasak". (responden Homestay B).

"Sekarang, kita merancang aktiviti mengikut minat pelancong. Antara aktiviti baharu adalah mendaki bukit, merentasi hutan dan menyelusuri sungai". (responden Homestay C).

Pembaharuan pakej ini merupakan ilham komuniti dalam menggunakan sumber semula jadi yang terdapat di kampung tersebut dan ianya turut dilakukan oleh Homestay A, D, E, F dan G.

Penambahbaikan turut dilakukan terhadap acara kebudayaan dengan keunikan tersendiri. Menurut responden Homestay F, inovasi yang dilakukan untuk mempamerkan seni kebudayaan adalah:

"Kami menyediakan aktiviti baharu iaitu mencating batik. Pelancong akan melihat demonstrasi dan dapat mempelajari cara mewarna batik tersebut. Hasil kerja yang dilakukan boleh dibawa pulang oleh setiap pelancong sebagai cenderahati”.
Sementara itu, terdapat juga program homestay yang menjemput penari daripada luar ekoran daripada generasi terdahulu yang sudah tidak berupaya untuk membuat persembahan. Penambahbaikan ini berdasarkan kenyataan responden Homestay H dan G iaitu:

"Warga tua di sini sudah tidak larat dan budak muda tidak berminat dengan tarian. Jadi, kita panggil kumpulan daripada Jabatan Kebudayaan dan Kesenian untuk mempersembahkan tarian seperti dondang sayang dan joget lambak”. (responden Homestay H).

"Aktiviti kebudayaan di sini masih dipertontonkan dengan menjemput pelajar sekolah seperti pasukan kompang dan tarian. Kita akan memberi upah kepada sekolah terlibat”. (responden Homestay G).

Inisiatif sebegini turut dinyatakan oleh responden Homestay B, C, D dan E bertujuan untuk mengekalkan acara kebudayaan sebagai tontotan pelancong. Selain itu, penambahbaikan juga dilakukan dalam penyediaan makanan tempatan dengan menginovasikan menu yang disediakan seperti ulasan responden Homestay A dan E:

"Homestayinitelahmencipta menu baharumenggunakan madu kelulut dalam masakan kampung seperti sup kambing herba madu kelulut dan sambal tumis udang galah madu kelulut”. (responden Homestay A).

"Kini, kita menyediakan makanan yang berbeza iaitu nasi lemak sambal strawberi. Ada juga dihidangkan serunding strawberi untuk dimakan dengan nasi". (responden Homestay E).

Kelainan yang ditonjolkan ini berupaya menarik minat pelancong mencuba resepi yang unik. Begitu juga dengan penambahbaikan kaedah penyediaan makanan yang dilakukan secara gotong-royong bersama pelancong. Responden Homestay B, D, E dan $\mathrm{H}$ berkongsi pakej aktiviti tersebut di mana responden Homestay H menyatakan:

"Pakej terkini adalah masakbersama-sama pelancong. Kita akan membeli bahan mentah untuk membuat asam pedas, kemudian menunjukkan cara bersiang ikan, memotong bahan-bahan dan masak menu tersebut bersama-sama. Pelancong akan teruja merasa masakan masing-masing”.

Inisiatif ini dapat mewujudkan suasana kampung yang lebih meriah antara pelancong dan komuniti.

Perkembangan Perusahaan IKS Semua responden menceritakan inovasi yang dilakukan terhadap perusahaan IKS daripada segi penambahbaikan terhadap pertambahan bilangan usahawan dan kepelbagaian jenis keluaran. Bilangan usahawan semakin bertambah terutamanya dalam perusahaan produk berasaskan makanan seperti kuih tradisional. Ini dibuktikan melalui kenyataan responden Homestay D: 
"Di sini, usahawan yang mengusahakan kerepek pisang dan bahulu semakin meningkat bagaikan cendawan tumbuh. Apabila permintaan pelancong dan pasaran tinggi, ramai komuniti turut terlibat menghasilkan keluaran tersebut".

Dapatan ini selari dengan ulasan responden Homestay A, B, C, E, F, G dan H yang juga mempunyai bilangan usahawan yang semakin meningkat dalam perusahaan pelbagai jenis keluaran berasaskan makanan.

Di samping itu, semua responden turut menyatakan kecenderungan untuk meningkatkan pelbagai jenis keluaran. Didapati beberapa program homestay telah menceburi dalam perusahaan berasaskan tanaman (responden Homestay B, C, E dan G). Responden E mengulas:

"Homestay terkenal dengan tanaman strawberi. Tanaman ini semakin berkembang sama ada diusahakan oleh pengusaha homestay atau komuniti lain. Ini bagi memudahkan pelancong menikmati pengalaman di ladang strawberi di samping membantu menambah pendapatan mereka".

Sementara itu, responden Homestay A, B, C, D dan $\mathrm{G}$ pula berkongsi perkembangan dalam penternakan dan perikanan. Responden Homestay C menceritakan:

"Di sini ada lawatan IKS bagi yang minat dalam penternakan seperti lembu. Usahawan kita juga ada yang mengusahakan ikan dalam kanvas. Jadi, pelancong yang datang akan dibawa melawat ke lokasi tersebut untuk merasai pengalaman memberi makan dan mempelajari kaedah ternakan”.

Di samping itu, kepelbagaian perusahaan ini memberi peluang kepada pelancong mengetahui cara hidup dan sumber pendapatan komuniti tempatan. Berbeza dengan responden Homestay $\mathrm{F}$ yang mengetengahkan perusahaan kraftangan dalam program homestay iaitu:

"Usahawan kraf telah mengembangkan perusahaan ukiran kayu untuk dijual dan dijadikan cenderahati. Ianya diusahakan secara individu dan kini telah mempunyai bengkel sendiri di mana pelancong boleh melihat dan merasai pengalaman membuat kraftangan tersebut".

Dapatan ini seiring dengan perkongsian responden Homestay $\mathrm{C}$ dan $\mathrm{H}$, sebagai usaha memperkenalkan industri desa kepada pelancong. Tambahan lagi, terdapat juga usahawan yang memperkenalkan perusahaan baharu berasaskan kecantikan sebagaimana dinyatakan oleh Responden A:

"Kumpulan wanita di sini telah menghadiri kursus untuk menghasilkan produk kecantikan daripada madu lebah kelulut iaitu minuman kesihatan dan sabun muka".
Hasil keluaran ini telah dipasarkan secara meluas kepada pelancong yang datang. Inisiatif ini dilihat bukan sahaja dapat meningkatkan kedatangan pelancong, malah melahirkan lebih ramai lagi usahawan desa.

\section{FAKTOR PENENTU INOVASI}

Dapatan kajian menunjukkan inovasi produk yang dilakukan dalam program homestay dipengaruhi oleh empat faktor penentu iaitu orientasi pasaran, semangat keusahawanan, sokongan kerajaan dan pengetahuan.

Orientasi Pasaran Pelaksanaan inovasi produk telah dipengaruhi oleh orientasi pasaran yang memfokuskan kepada permintaan pelancong. Ini dibuktikan oleh responden Homestay A yang mengambil kira maklum balas pelancong iaitu:

"Kita sentiasa memperbaiki mengikut aduan dan cadangan pelancong. Jika ada komen negatif, kita sentiasa cuba menambah baik seperti tahap kebersihan dan kemudahan di dalam bilik".

Begitu juga dengan pembaharuan terhadap konsep penginapan adalah juga didorong oleh permintaan pelancong untuk tinggal berasingan daripada tuan rumah. Responden Homestay F menyatakan:

"Idea mewujudkan kampungstay datangnya daripada pelancong. Apabila mendapat sambutan yang tinggi, pengusaha telah membangunkan pelbagai pilihan bilik kepada pelancong dan ianya amat menguntungkan".

Faktor penentu ini turut diakui oleh responden Homestay B, C, D, E, G dan $\mathrm{H}$ dalam usaha untuk memenuhi kehendak pasaran masa kini. Selain itu, perubahan minat pelancong juga telah mendorong kepada penciptaan pelbagai aktiviti baharu. Responden Homestay C menghuraikan:

"Apabila hendak menyediakan pakej aktiviti, kita perlu mengikut tren pelancong. Sekarang, ramai yang suka aktiviti air, ke hutan dan bukit. Jadi, kita telah menyediakan aktiviti sebegini bagi menarik ramai pelancong”.

Pembaharuan ini juga dihuraikan oleh responden Homestay A, B, D dan E yang turut mengambil kira minat dan kehendak pelancong masa kini yang lebih gemarkan aktiviti lasak terutamanya golongan muda dan daripada luar negara.

Semangat Keusahawanan Komuniti yang terlibat dalam program homestay mempunyai semangat keusahawanan yang tinggi untuk menawarkan produk yang berinovasi. Menurut responden Homestay F:

"Pengusaha sememangnya mempunyai minat mendalam dalam program homestay dan akan berusaha 
menyediakan penginapan dan pakej aktiviti yang menarik kepada pelancong”.

Ini juga diakui oleh responden Homestay A dan $\mathrm{G}$ yang mempunyai usahawan kreatif dan sentiasa berinisiatif di mana:

"Kami sentiasa mencari idea baharu untuk aktiviti pelancongan. Ada juga idea diperolehi semasa berkunjung ke Sabah iaitu aktiviti menyelusuri sungai. Kampung ini juga mempunyai sungai, jadi kami wujudkan aktiviti yang sama”. (responden Homestay A)

"Pengusaha homestay sentiasa mempunyai inisiatif untuk melakukan perubahan dengan menyusun atur, mengubahsuai bilik air dan membina bilik baharu secara perlahan-lahan untuk kepuasan pelancong". (responden Homestay G)

Inovasi yang dilakukan juga didorong oleh semangat untuk lebih berusaha bagi menambah pendapatan. Begitu juga dengan usahawan IKS yang turut meningkatkan keluaran mereka agar memperolehi keuntungan yang lumayan. Responden Homestay C berhujah:

"Pengusaha dan usahawan IKS sentiasa berusaha meningkatkan pendapatan dengan menambah baik perniagaan masing-masing. Ini akan menggalakkan pelancong menyertai program homestay dan membeli keluaran mereka".

Ini membuktikan semangat keusahawanan adalah penting dalam mempengaruhi inovasi produk dan diakui oleh semua responden.

Sokongan Kerajaan Sokongan kerajaan juga telah banyak mempengaruhi perkembangan program homestay. Pengusaha semakin bijak menghasilkan sesuatu yang lebih baik kepada pelancong melalui program yang disediakan oleh pihak kerajaan. Responden Homestay C turut menyatakan:

"Kursus yang disediakan oleh kerajaan telah memberi kesedaran kepada komuniti agar sentiasa bersedia dan mempunyai keyakinan membuat perubahan untuk lebih berjaya”.

Ini membuktikan komuniti telah menggunakan latihan yang dipelajari untuk meningkatkan program homestay masing-masing. Responden Homestay A menghuraikan:

"Semua pengusaha homestay telah menghadiri kursus anjuran KEDA dan pejabat pelancongan. Sekarang mereka sudah pandai menyediakan makanan yang menarik, memasang cadar dengan kemas dan cara menyambut tetamu yang betul”.

Kenyataan ini turut diakui oleh responden Homestay B, C, D, E, F, G dan H, di mana sokongan kerajaan telah menyokong usaha menaik taraf ruang penginapan. Selain itu, sokongan kerajaan juga berbentuk pemberian insentif sebagaimana peruntukan yang diterima oleh Homestay A, B, G dan $\mathrm{H}$, telah berupaya meningkatkan kualiti penginapan. Responden Homestay B dan $\mathrm{H}$ mengulas:

"Peruntukan berjumlah RM5,000 telah diterima oleh setiap pengusaha dan digunakan untuk membaiki bilik air untuk keselesaan pelancong”. (responden Homestay B)

"Dana telah diberikan oleh kerajaan untuk mengecat semula rumah. Ada juga pengusaha yang menerima peruntukan bagi menambah bilik untuk pelancong”. (responden Homestay $H$ )

Insentif yang diberikan telah menggalakkan penyediaan ruang penginapan yang lebih baik sekaligus menjadi satu tarikan untuk pelancong berkunjung ke homestay tersebut.

PengetahuanPengetahuan yang dimiliki juga penting dalam usaha menyediakan produk yang berinovasi. Pengetahuan berbentuk kemahiran diterangkan oleh responden Homestay E:

"Komuniti di sini mempunyai pelbagai kemahiran yang diwarisi. Kelebihan ini dapat menggalakkan penciptaan pelbagai produk dan aktiviti yang boleh menarik kedatangan pelancong".

Didapati kemahiran yang dimiliki telah mampu memartabatkan kebudayaan dan warisan melalui aktiviti yang dipersembahkan. Contohnya dihuraikan oleh responden Homestay $\mathrm{H}$ dan F:

“...terdapat juga komuniti yang mengikuti kursus gamelan dalam kampung ini. Jadi mereka akan bermain alat muzik semasa acara sambutan". (responden Homestay H)

"Anak muda di sini mahir dalam silat dan gasing. Aktiviti ini boleh dipertontonkan kepada pelancong dan mereka dapat melihat teknik pembuatan gasing di galeri yang disediakan". (responden Homestay F)

Pengetahuan ini telah digunakan dalam usaha menambah aktiviti baharu dengan penyusunan pakej yang lebih menarik untuk ditawarkan kepada pelancong. Dapatan ini seiring dengan penjelasan responden Homestay A, B, C, E, F dan G.

Selain itu, faktor pengetahuan juga telah mempengaruhi perkembangan perusahaan IKS sepertimana dihuraikan oleh responden Homestay D:

"Orang kampung di sini mempunyai kemahiran membuat kuih tradisional seperti kerepek, dodol dan bahulu. Apabila pelancong datang, mereka boleh menunjukkan cara pembuatan kepada pelancong. Permintaan juga 
semakin meningkat kerana pelancong suka menikmati produk tempatan".

Pengetahuan sebegini turut dikongsikan oleh responden Homestay A, B, C, F, G dan H. Keaslian rasa dan teknik pembuatan kuih tradisional merupakan satu keunikan yang berharga dalam mempengaruhi komuniti untuk lebih berinovasi.

\section{PERBINCANGAN}

Penemuan dalam kajian ini menunjukkan pelaksanaan inovasi produk dalam program homestay telah berjaya menarik minat sekaligus meningkatkan kedatangan pelancong. Dapatan ini selari dengan kajian terdahulu yang turut membuktikan berlakunya inovasi produk dalam sektor pelancongan amnya (Cosma et al. 2014; Martínez-Román et al. 2015; Nicolau \& Santa-María 2013; Nieves et al. 2014; Sakdiyakorn \& Sivarak 2016) dan program homestay khususnya (Hashim et al. 2015; Keling \& Entebang 2017; Suffarruddin et al. 2017). Inovasi yang telah dilaksanakan merangkumi tiga kategori iaitu peningkatan kualiti ruang penginapan, keunikan pakej aktiviti desa dan perkembangan perusahaan IKS.

Penemuan kajian menunjukkan inovasi paling ketara ialah terhadap peningkatan kualiti ruang penginapan. Antara pembaharuan paling menarik adalah dengan mentranformasikan satu konsep penginapan baharu dikenali sebagai kampungstay. Inovasi lain turut dilakukan merangkumi pemasangan penyaman udara dan pengubahsuaian bilik air agar dapat memberi keselesaaan kepada pelancong. Pembaharuan dan penambahbaikan ini merupakan inisiatif pengusaha dalam memenuhi kehendak pelancong yang mana turut menyokong penemuan Ernawati et al. (2017) dan Jin, Ling dan Fern (2016) sebagi usaha mengutamakan privasi pelancong. Ini seiring dengan cadangan kajian terdahulu (Hashim et al. 2015; Keling \& Entebang 2017) yang mencadangkan program homestay perlu memfokuskan kepada penyediaan pelbagai jenis penginapan untuk lebih kompetitif. Tambahan lagi, penginapan merupakan produk utama yang ditawarkan kepada pelancong sebagaimana ditemui dalam kajian Aziz dan Othman (2015) dan Kayat (2011).

Di samping itu, keunikan pakej aktiviti desa turut diberi perhatian utama agar pelancong merasai pengalaman kehidupan di desa yang lebih menyeronokkan. Eksplorasi aktiviti lasak merupakan salah satu pakej terbaharu yang ditawarkan kepada pelancong. Dapatan ini seiring dengan kajian Ahmad et al. (2011) yang membuktikan aktiviti sebegini dapat memberi peluang kepada pelancong untuk menikmati keindahan alam semula jadi sekaligus memperkenalkan kawasan luar bandar yang kaya dengan sumber alam (Hussin \& Kunjuraman 2014). Selain itu, usaha untuk melestarikan kebudayaan dan kesenian turut diberi keutamaan melalui kelainan yang ditonjolkan dalam persembahan kebudayaan dan penyediaan makanan tradisional. Penemuan ini menyokong saranan MOTAC untuk menawarkan kepelbagaian pengalaman gaya hidup masyarakat kampung (Hashim et al. 2015; Keling \& Entebang 2017) melalui keunikan pakej aktiviti yang mampu menjadi daya tarikan kepada pelancong (Razzaq et al. 2011).

Dalam program homestay, perkembangan perusahaan IKS juga merupakan inovasi produk yang ditemui dalam kalangan usahawan desa. Antara keluaran yang dihasilkan adalah barangan berasaskan makanan, pertanian, kraftangan dan kecantikan. Penambahbaikan yang telah dilakukan adalah berbentuk peningkatan bilangan usahawan terlibat dan kepelbagaian hasil keluaran. Lebih unik lagi, perusahaan IKS adalah berasaskan sumber yang berbeza daripada setiap kampung seperti tanaman, penternakan dan perikanan. Kepelbagaian produk IKS ini merupakan satu keunikan yang dapat menarik kedatangan pelancong dengan memperkenalkan produk kampung (Keling \& Entebang 2017). Inovasi ini menunjukkan bahawa program homestay berupaya menonjolkan identiti tradisional melalui aktiviti demonstrasi dan penghasilan produk tempatan oleh perusahaan IKS yang telah dimanfaatkan secara meluas (Selamat \& Swamithan 2015; Ismail 2015). Penemuan ini menunjukkan program homestay berupaya melahirkan lebih ramai usahawan desa dan sekaligus membuktikan bahawa inovasi terhadap aktiviti pelancongan dapat membangunkan ekonomi setempat (Ahmad et al. 2017).

Kajian ini turut mendapati bahawa pelaksanaan inovasi produk adalah didorong oleh beberapa faktor penentu. Ini selari dengan kajian terdahulu yang turut menemui beberapa faktor penentu inovasi yang berbeza mengikut jenis pelancongan seperti pelancongan budaya warisan (Sakdiyakorn \& Sivarak 2016), pelancongan PKS (Martínez-Román et al. 2015; Mei et al. 2011), perhotelan (Nieves et al. 2014) dan penginapan luar bandar (Raffai 2013). Dalam kajian ini, empat faktor penentu inovasi produk yang ditemui adalah orientasi pasaran, semangat keusahawanan, sokongan kerajaan dan pengetahuan.

Dalam program homestay, orientasi pasaran merupakan faktor penentu yang paling signifikan di mana perubahan permintaan telah banyak mendorong pelaksanaan inovasi. Setiap program homestay begitu peka terhadap tren masa kini agar dapat menjana idea yang lebih kreatif. Begitu juga komen dan cadangan yang diberikan oleh pelancong amat penting untuk melakukan penambahbaikan ke atas produk yang ditawarkan. Penemuan ini menyokong kajian Raffai (2013) dan Ronningen (2010) tentang kepentingan kesedaran terhadap permintaan pelancong dalam memenuhi pasaran masa kini. Faktor penentu ini juga mendorong keinginan komuniti untuk terus berusaha dan berdaya maju (Sakdiyakorn \& Sivarak 2016). Selain itu, semangat keusahawanan yang kuat dalam kalangan 
pengusaha dan komuniti juga merupakan faktor penentu yang mendorong keinginan melakukan inovasi produk. Mereka dilihat sentiasa berfikiran kreatif dalam membuat kelainan terhadap produk di samping meningkatkan pendapatan yang lebih baik. Penemuan ini disokong oleh kajian Bukhari et al. (2012) dan Sakdiyakorn dan Sivarak (2016) yang mendapati semangat keusahawanan yang kuat penting untuk menggalakkan usahawan lebih berinovasi.

Seterusnya adalah sokongan kerajaan yang juga ditemui sebagai faktor penentu inovasi produk. Majoriti responden mengakui bahawa sokongan kerajaan berbentuk penyediaan kursus dan pemberian insentif penting dalam melahirkan pengusaha yang berinovasi dan mampu meningkatkan kualiti penginapan. Kursus yang disediakan oleh pihak kerajaan dapat memberi pendedahan dalam menguruskan penginapan yang lebih kompetitif. Begitu juga dengan peruntukan yang disalurkan berupaya membantu pengusaha menyediakan penginapan yang lebih selesa untuk memenuhi kehendak pelancong. Penemuan ini menyokong kajian Raffai (2013) yang mendapati penyediaan kursus dapat menggalakkan inovasi dalam pelancongan luar bandar, manakala kajian Mei et al. (2011) membuktikan pembiayaan kerajaan juga penting sebagai pendorong kepada inovasi produk pelancongan.

Selain itu, pengetahuan dalam kalangan komuniti juga merupakan faktor penentu inovasi yang ditemui telah mempengaruhi inovasi produk dalam program homestay. Majoriti daripada mereka telah menggunakan pengetahuan berbentuk kemahiran yang dimiliki dan diwarisi secara turun temurun untuk memberikan kelainan terhadap produk seperti pembuatan makanan tradisional, persembahan kebudayaan dan keluaran IKS. Penemuan ini membuktikan pengetahuan merupakan nilai tambah yang penting untuk membantu dalam meningkatkan keuntungan sesebuah perniagaan (Tajeddini et al. 2020). Ini selari dengan pengkaji dalam industri pelancongan yang mendapati pengetahuan dapat menyumbang kepada penghasilan idea baharu dan mendorong kepada pelaksanaan inovasi secara berterusan (Martinez-Roman et al. 2015; Nieves et al. 2014). Penemuan ini disokong oleh kajian Sakdiyakorn dan Sivarak (2016) yang menjelaskan pengetahuan menjadi asas untuk lebih peka dalam melakukan inovasi agar seiring dengan perkembangan masa kini. Oleh itu, pengetahuan perlu sentiasa dipertingkatkan supaya dapat menyumbang kepada pelaksanaan inovasi produk yang lebih kreatif.

\section{KESIMPULAN}

Hasil kajian ini membuktikan bahawa pelaksanaan inovasi produk amat penting dalam pelancongan luar bandar termasuklah program homestay. Produk yang ditawarkan dalam beberapa program homestay di Semenanjung Malaysia telah melalui fasa pembaharuan dan penambahbaikan yang boleh dibahagikan kepada tiga kategori utama iaitu daripada segi peningkatan kualiti penginapan, keunikan pakej aktiviti desa dan perkembangan perusahaan IKS. Ketiga-tiga produk ini merupakan tarikan utama dalam mempromosikan program homestay dan sekaligus memberi kepuasan kepada pelancong. Penerokaan yang dilakukan juga telah menemui empat faktor penentu kepada inovasi produk iaitu orientasi pasaran, semangat keusahawanan, sokongan kerajaan dan pengetahuan. Faktor penentu merupakan pendorong utama kepada pembentukan idea kreatif bagi melahirkan keunikan dan kelainan produk yang berbeza dalam setiap program homestay.

Penemuan kajian ini telah menyumbang kepada ilmu pengetahuan baharu yang menekankan bahawa keupayaan melaksanakan inovasi dalam program homestay untuk lebih berdaya saing adalah didorong oleh beberapa faktor penentu. Sejajar dengan itu, tahap kesediaan dan komitmen yang tinggi dalam kalangan komuniti amat diperlukan untuk menjana kreativiti dan inovasi. Ini bagi memastikan produk yang ditawarkan seiring dengan perkembangan pelancongan masa kini. Hasil kajian ini juga diharapkan berupaya memberi implikasi dan sumbangan penting kepada program homestay yang lain untuk lebih berinovasi. Berdasarkan penekanan terhadap tiga kategori produk yang utama, idea ini dapat memberi pendedahan kepada pemain industri untuk melakukan pembaharuan dan penambahbaikan yang boleh menjana ekonomi dan seterusnya melahirkan lebih ramai lagi usahawan desa. Bagi merealisasikan inovasi ini, setiap peserta dalam program homestay disarankan agar lebih peka dengan persekitaran yang berupaya menjadi faktor penentu inovasi. Lantaran itu, semua pihak termasuk penyelaras, pengusaha dan komuniti adalah digalakkan untuk lebih fokus kepada kepentingan inovasi yang memerlukan perancangan dan kepelbagaian idea kreatif.

Limitasi yang dikenal pasti dalam kajian ini adalah berkaitan jenis inovasi yang diterokai hanya tertumpu kepada inovasi produk. Selain itu, responden bagi setiap program homestay juga terhad kepada penyelaras sahaja kerana terdapat kesukaran berjumpa dengan pengusaha homestay yang majoritinya pula merupakan golongan berusia dan sukar untuk berkomunikasi dengan baik. Oleh itu, dicadangkan agar kajian pada masa hadapan dapat menerokai pelaksanaan jenis inovasi lain dalam program homestay. Akhir sekali, kajian lanjutan boleh dilakukan berkaitan persepsi pelancong terhadap keunikan program homestay untuk membantu pengusaha meningkatkan kualiti produk yang ditawarkan.

\section{RUJUKAN}

Abdul Aziz, N.I., Hassan, F. \& Jaafar, M. 2014. Exploring tourist experiences in Kampung Beng homestay programme. Asia-Pacific Journal of Innovation in Hospitality and Tourism 3(1): 21-40.

Ahmad, H., Mohamad, A.H., Jusoh, H., Mahmud, M., Azman, H., Ramli, S., \& Zin, A.M. 2017. Aset pelancongan luar bandar dari lensa komuniti Lembah Beriah (Rural tourism 
assets from the community perspective of Lembah Beriah). Geografia-Malaysian Journal of Society and Space 13(1): 87-100.

Ahmad, M.Z, Ibrahim, J.A \& Zakaria, N. 2011. Homestay as a socioeconomic community development Agent From UUM tourism management student's perspective. Prosiding PERKEM VI, Jilid 2: 481-493.

Ahmad, S.Z., Jabeen, F. \& Khan, M. 2014. Entrepreneur's choice in business venture: Motivations for choosing homestay accommodation business in Peninsular Malaysia International Journal of Hospitality Management 36: 3140.

Al-Ansari, Y., Pervan, S., \& Xu, J. 2013. Innovation and business performance of SMEs: The case of Dubai Education, Business and Society: Contemporary Middle Eastern Issues 6(3/4): 162-180.

Alberti, F.G., \& Giusti, J.D. 2012. Cultural heritage, tourism and regional competitiveness: The Motor Valley cluster. City, Culture and Society 3(4): 261-273.

Aldebert, B., Dang, R.J., \& Longhi, C. 2011. Innovation in the tourism industry: The case of Tourism@. Tourism Management 32: 1204-1213.

Alsos, G.A., Eide, D., \& Madsen, E.L. (Eds.). 2014. Handbook of Research on Innovation in Tourism Industries. United Kingdom: Edward Elgar Publishing.

Aziz, Y.A. \& Othman, M. 2015. Persepsi komuniti tempatan terhadap program homestay di Malaysia. Dlm. Program Homestay dan Pembangunan Komuniti Luar Bandar di Malaysia, disunting oleh Mapjabil J., 78-101). Sintok: Universiti Utara Malaysia Press.

Backman, M., Klaesson, J., \& Öner, Ö. 2017. Innovation in the hospitality industry: Firm or location? Tourism Economics 23(8): 1591-1614.

Bhuiyan, M.A.H., Siwar, C., Ismail, S.M., \& Islam, R. 2012. Home stay accommodation for tourism development in East Coast Economic Region. American Journal of Applied Sciences 9(7): 1085-1090.

Birgit, P., Mike, P. \& Chung-Shing, C. 2018. Needs, drivers and barriers of innovation: The case of an alpine communitymodel destination. Tourism Management Perspectives 25: 53-63.

Boachie-Mensah, F. \& Aquah, I.S.K. 2015. The effect of innovation types on the performance of small and mediumsized enterprises in the Sekondi-Takoradi Metropolis. Archives of Business Research 3(3): 77-98.

Bodlaj, M., Coenders, G. \& Zabkar, V. 2012. Responsive and proactive market orientation and innovation success under market and technological turbulence. Journal of Business Economics and Management 13(4): 666-687,

Bukhari, M., Munif, A., \& Faiz Hilmi, M. 2012. Challenges and outcome of innovative behavior: A qualitative study of tourism related entrepreneurs. Journal of Technology Management \& Innovation 7(2): 131-143.

Camisón, C., \& Monfort-Mir, V.M. 2012. Measuring innovation in tourism from the Schumpeterian and the dynamiccapabilities perspectives. Tourism Management 33(4): 776-789.

Chang, W., Franke, G.R., Butler, T.D., Musgrove, C.F., \& Ellinger, A.E. 2014. Differential mediating effects of radical and incremental innovation on market orientationperformance relationship: A meta-analysis. Journal of Marketing Theory and Practice 22(3): 235-250.

Chang, Y., Linton, J. \& Chen, M. 2012. Service regime: An empirical analysis of innovation patterns in service firms.
Technological Forecasting \& Social Change 79(10): 1569-1582.

Cosma, S., Paun, D., Bota, M., \& Fleseriu, C. 2014. Innovation-a useful tool in the rural tourism in Romania. Procedia-Social and Behavioral Sciences 148: 507-515.

Creswell, J.W. 2014. Educational Research: Planning, Conducting and Evaluating Quantitative and Qualitative Research. 4th Ed.. Harlow: Pearson.

Croitoru, A. 2012. Schumpeter, JA, 1934. 2008. The theory of economic development: an inquiry into profits, capital, credit, interest and the business cycle, translated from the German by Redvers Opie, New Brunswick (USA) and London (UK): Transaction Publishers. Journal of Comparative Research in Anthropology and Sociology 3(2): 1-13.

Crumpton, M.A. 2012. Innovation and entrepreneurship. The Bottom-Line Managing Library Finances 25(3): 98-101.

Divisekera, S., \& Nguyen, V. K. 2018. Determinants of innovation in tourism evidence from Australia. Tourism Management 67: 157-167.

EPU. 2015. Elevating B40 Households towards a middle-class society. Strategy Paper, 2. Putrajaya: Economic Planning Unit, Malaysia: Prime Minister's Department.

Ernawati, N.M., Sanders, D., \& Dowling, R. 2017. Host-Guest Orientations of Community-based Tourism Products: A Case Study in Bali, Indonesia. International Journal of Tourism Research 19(3): 367-382.

Galindo, M.Á., \& Méndez-Picazo, M. T. 2013. Innovation, entrepreneurship and economic growth. Management Decision 51(3): 501-514

Gunday, G., Ulusoy, G., Kilic, K., \& Alpkan, L. 2011. Effects of innovation types on firm performance. International Journal of Production Economics 133(2): 662-676.

Hashim, A. M., Jamalludin, N., Nor, M. N. M., Nazrin, N., Merican, F. M. I. \& Ahmad, S. S. 2015. Langkawi Homestay: Exploring an innovation aspect in homestay industry. Journal of Tourism, Hospitality and Sports 8: 14-19.

Hjalager, A.M. 2010. A review of innovation in tourism. Tourism Management 1(1): 1-12.

Hjalager, A.M., Kwiatkowski, G., \& Østervig Larsen, M. 2018. Innovation gaps in Scandinavian rural tourism. Scandinavian Journal of Hospitality and Tourism 18(1): 1-17.

Hussin, R. \& Kunjuraman, V. 2014. Pelancongan mapan berasaskan komuniti (CBT) melalui program homestay di Sabah, Malaysia. GEOGRAFIA - Malaysian Journal of Society and Space 10(3): 160-174.

Ibrahim, Y., \& Razzaq, A.R.A. 2010. Homestay program and rural community development in Malaysia. Journal of Ritsumeikan Social Sciences and Humanities 2(3): 7-24.

Ismail, H.N. 2015. Pertimbangan kriteria asas pemilihan destinasi dalam pembangunan program homestay di Malaysia. Dlm. Program Homestay dan Pembangunan Komuniti Luar Bandar di Malaysia, disunting oleh Mapjabil J., 49-64. Sintok: Universiti Utara Malaysia Press.

Jin, S.T.T., Ling, T.C., \& Fern, Y.S. 2016. What are the attractiveness aspects that influence customer loyalty to homestays? A study in Taiwan. Jurnal Pengurusan 48: 201-208.

Kafetzopoulos, D. \& Psomas, E. 2015. The impact of innovation capability on the performance of manufacturing 
companies, The Greek case. Journal of Manufacturing Technology Management 26(1): 104-130.

Kalyani, M. 2011. Innovative culture: An intervention strategy for sustainable growth in changing scenario. International Journal of Business Administration 2(4): 84-92.

Kasim, M.M., Kayat, K. \& Ramli, R. 2016. Sustainability criteria for the Malaysia Homestay Program. International Review of Management and Marketing 6(S7): 250-255.

Kayat, K. 2011. Homestay Programme as a Malaysian Tourism Product. Sintok: Universiti Utara Malaysia Press

Keling, W., \& Entebang, H. 2017. Dayak Homestay entrepreneur's innovation characteristics. Ottoman: Journal of Tourism and Management Research 2(2): 101112.

Kementerian Pelancongan dan Kebudayaan, MOTAC. 2020. Program Homestay Malaysia. Diakses daripada http:// www.motac.gov.my

Kuratko, D.F. \& Hodgetts, R.M. 2004. Entrepreneurship: Theory, Process and Practices. $6^{\text {th }}$ edition. USA: Smith Western.

Mapjabil J. \& Ismail S.C. 2015. Program homestay dan pembangunan sosioekonomi luar bandar di Malaysia. Dlm. Program Homestay dan Pembangunan Komuniti Luar Bandar di Malaysia, disunting oleh Mapjabil J., 2748. Sintok: Universiti Utara Malaysia Press.

Mapjabil, J., Ismail, S.C., Ab Rahman, B., Masron, T., Ismail, R., \& Zainol, R. M. 2017. Homestays-community programme or alternative accommodation? A re-evaluation of concept and execution. Geografia-Malaysian Journal of Society and Space 11(12): 1-8.

Martinez, E.V., Serna, C.M., \& Guzman, G.M. 2018. The relationship between market orientation, entrepreneurial orientation and learning orientation on innovation and its effect on performance in Mexican SMEs. International Business Management 12(2): 132-144.

Martínez-Román, J.A., Tamayo, J A., Gamero, J., \& Romero, J.E. 2015. Innovativeness and business performances in tourism SMEs. Annals of Tourism Research 54: 118-135.

Mei, X. Y., Arcodia, C., \& Ruhanen, L. 2011. A national government's tourism innovation initiatives: A review of tourism development policies in Norway. In The 21st Council for Australian University Tourism and Hospitality Education Annual Conference (CAUTHE 2011), 1-20.

Najda-Janoszka, M., \& Kopera, S. 2014. Exploring barriers to innovation in tourism industry-the case of southern region of Poland. Procedia-Social and Behavioral Sciences 110: 190-201.

Nicolau, J.L., \& Santa-María, M.J. 2013. The effect of innovation on hotel market value. International Journal of Hospitality Management 32: 71-79.

Nieves, J., Quintana, A., \& Osorio, J. 2014. Knowledgebased resources and innovation in the hotel industry. International Journal of Hospitality Management 38: 6573.

Organisation for Economic Co-operation and Development, OECD. 2005. Oslo Manual: Proposed Guidelines for Collecting and Interpreting Technological Innovation Data. Paris: OECD Publishing.

Osman, Z., \& Zakaria, Z. 2020. Factors influencing intention to adopt internet technology among rural homestay operators in Malaysia. Journal of Technology Management and Business 7(1): 25-35.

Raffai, C. 2013. Innovation in rural tourism: a model for Hungarian Accommodation providers. Management \& Marketing 8(4): 747-766.

Ramele, R., \& Yamazaki, J. 2020. The Malaysian homestay program and the Japanese minshuku: A comparative study. Environment-Behaviour Proceedings Journal 5(SI2): 5560.

Razzaq, A.R.A., Hadi, M.Y., Mustafa, M.Z., Hamzah, A., Khalifah, Z., \& Mohamad, N.H. 2011. Local community participation in homestay program development in Malaysia. Journal of Modern Accounting and Auditing 7(12): $1418-1429$

Ronningen, M. 2010. Innovation in the Norwegian Rural tourism industry: Results from a Norwegian survey. The Open Social Science Journal 3: 15-29.

Rosli, M. M., \& Sidek, S. 2013. The impact of innovation on the performance of small and medium manufacturing enterprises: Evidence from Malaysia. Journal of Innovation Management in Small \& Medium Enterprise 2013: 1-16.

Sakdiyakorn, M. \& Sivarak, O. 2016. Innovation management in cultural heritage tourism: Experience from the Amphawa Waterfront Community, Thailand. Asia Pacific Journal of Tourism Research 21(2): 212-238.

Selamat, N.H. \& Swaminathan, K. 2015. Persembahan 'Kehidupan Desa' sebagai produk pelancongan di Homestay Kampung Relau, Kedah. Dlm. Program Homestay dan Pembangunan Komuniti Luar Bandar di Malaysia, disunting oleh Mapjabil J., 26-151. Sintok: Universiti Utara Malaysia Press.

Suffarruddin, S.H., Jaafar, M. \& Rahman, S. 2017. Inovasi produk dalam program homestay: Kajian kes di Homestay Kampung Desa Keda. Social Sciences Postgraduate International Seminar 2017: 165-172.

Tajeddini, K., Martin, E., \& Altinay, L. 2020. The importance of human-related factors on service innovation and performance. International Journal of Hospitality Management 85: 1-14.

Tidd, J., Bessant, J. \& Pavitt, K. 2005. Managing Innovation: Integrating Technological, Market and Organizational Change. New York: Wiley.

Yin, R.K. 2011. Qualitative Research from Start to Finish. New York: The Guilford Press.

Suhaida Herni Suffarruddin (penulis koresponden)

Pusat Pengajian Perumahan, Bangunan dan Perancangan,

Universiti Sains Malaysia,

11800 Pulau Pinang, MALAYSIA

E-Mel: suhaidasuff@gmail.com

Mastura Jaafar

Pusat Pengajian Perumahan, Bangunan dan Perancangan,

Universiti Sains Malaysia,

11800 Pulau Pinang, MALAYSIA

E-Mel: masturaj@usm.my

Suraiyati Rahman

Pusat Pengajian Perumahan, Bangunan dan Perancangan,

Universiti Sains Malaysia,

11800 Pulau Pinang, MALAYSIA

E-Mel: suraiyati@usm.my 